\title{
Can lymphovascular invasion replace the prognostic value of lymph node involvement in patients with upper tract urothelial carcinoma after radical nephroureterectomy?
}

\author{
Eun Sang Yoo, MD $;^{i^{*}}$ Yun-Sok Ha, MD; ${ }^{i^{*}}$ Jun Nyung Lee, MD; $;^{1}$ Bum Soo Kim, MD; ${ }^{\prime 1}$ Bup Wan Kim, MD; \\ Seok-Soo Byun, MD; ${ }^{2}$ Young Deuk Choi, MD, ${ }^{3}$ Ho Won Kang, MD, ${ }^{4}$ Seok-Joong Yun, MD, ${ }^{4}$ \\ Wun-Jae Kim, MD, Jeong Hyun Kim, MD, ${ }^{5}$ Tae Gyun Kwon, MD'
}

'Department of Urology, School of Medicine, Kyungpook National University, Daegu, Korea; ${ }^{2}$ Department of Urology, Seoul National University Bundang Hospital, Seongnam, Korea; ${ }^{3}$ Department of Urology and Urological Science Institute, Yonsei University College of Medicine, Seoul, Korea; ${ }^{4}$ Department of Urology, College of Medicine, Chungbuk National University, Cheongiu, Chungbuk, Korea; ${ }^{5}$ Department of Urology, Kangwon National University School of Medicine, Chuncheon, Republic of Korea.

*Equal contributors

Cite as: Can Urol Assoc J 2016;10(7-8):E229-36. http://dx.doi.org/10.5489/cuaj.3557 Published online July 12, 2016

\section{Abstract}

Introduction: This study aimed to evaluate whether lymphovascular invasion (LVI) can replace lymph node (LN) involvement as a prognostic marker in patients who do not undergo lymph node dissection (LND) during surgery in patients with upper tract urothelial carcinoma (UTUC).

Methods: A total of 505 patients who underwent radical nephroureterectomy (RNU) were recruited from four academic centres and divided into four groups: node negative (N0, Group 1); node positive (N+, Group 2); no LND without LVI (NxLVI-, Group 3); and no LND with LVI (NxLVI+, Group 4).

Results: Patients in Group 2 had larger tumours, a higher incidence of left-sided involvement, more aggressive $\mathrm{T}$ stage and grade, and a higher positive surgical margin rate than patients in other groups. Pathological features ( $T$ stage and grade) were poorer in Group 4 than in Groups 1 and 3. Compared to other groups, Group 2 had the worst prognostic outcomes regarding locoregional/distant metastasis-free survival (MFS), cancer-specific survival (CSS), and overall survival (OS). LVI and LN status in Group 4 was not associated with MFS in multivariate analysis. Among Nx diseases, LVI was not an independent predictor of MFS or CCS. The small number of cases in Groups 2 and 4 is a major limitation of this study. Conclusions: Clinical outcomes according to LVI did not correlate with those outcomes predicted by LN involvement in patients with UTUC. Therefore, LVI may not be used as a substitute for nodal status in patients who do not undergo LND at the time of surgery.

\section{Introduction}

The prevalence of upper tract urothelial carcinoma (UTUC) is approximately $5-10 \% .^{1-5}$ Approximately $20-40 \%$ of patients initially present with locally advanced disease and lymph node (LN) metastases at the time of diagnosis. ${ }^{6-9}$ Recently, Margulis et al identified age, high tumour grade, high pathological T stage, LN metastasis, sessile architecture, an infiltrative growth pattern, and lymphovascular invasion (LVI) as independent prognostic indicators of disease recurrence and cancer-specific survival (CSS). ${ }^{8}$ Tumour stage, grade, and LVI are independent predictors of clinical outcome in patients with UTUC; ${ }^{10,11}$ however, knowledge of assessable prognostic factors in UTUC is still limited.

Radical nephroureterectomy (RNU) with excision of the ipsilateral bladder cuff is the treatment of choice for localized UTUC. ${ }^{12}$ In most retrospective studies on UTUC treated by RNU, LVI is detected in approximately $20 \%$ of cases. ${ }^{13}$ LVI is a critical step in the systemic dissemination of cancer cells. ${ }^{14} \mathrm{LVI}$ is also associated with high stage and grade, and has a negative impact on UTUC prognosis. ${ }^{15-18}$ Metastasis of UTUC to regional LNs occurs frequently and is a significant predictor of oncologic outcomes. $\mathrm{LN}$ dissection (LND) is highly recommended in muscle-invasive UTUC; ${ }^{10,19}$ however, LND for UTUC is not universally performed. A recent study presented at the American Urological Association $(A \cup A)$ annual meeting suggested that $L V I$ is associated with LN involvement in patients with UTUC and may be used as a surrogate marker in patients who do not undergo LND at the time of surgery..$^{20}$ In that study, no differences in oncologic outcomes were observed between node positive $(\mathrm{N}+)$ and LVI positive patients who did not undergo LND (NxLVI+); 
Yoo et al.

however, limitations of the study, such as the small study population $(n=131)$, prevent definitive conclusions.

To address this issue, a large multicentre cohort of patients with UTUC who underwent RNU was analyzed for the first time. The aim of the present study was to evaluate whether LVI can be used as a prognostic substitute for LN involvement in patients who do not undergo LND during surgery in a large cohort.

\section{Methods}

\section{Study population}

Data obtained from 505 patients who underwent RNU (open, 183 [36.2\%], or laparoscopic, 322 [63.8\%]) for UTUC at four institutions in Korea between March 2001 and December 2013 were analyzed. All of the patients had complete followup data available and were considered for the analyses. To avoid the introduction of bias in the survival estimates, patients with previous or concurrent muscleinvasive bladder cancer, those who received neoadjuvant chemotherapy, or those with evidence of distant metastasis at the time of diagnosis were excluded. Patients had undergone preoperative cystoscopy, urine cytology, and chest and abdominal-pelvic computed tomography (CT) scans.

Surgery was performed according to the standard criteria for RNU. After RNU, bladder cuff resection was performed using standard procedures (i.e., an extravesical approach via a Gibson incision) as stipulated by each centre. LND was performed if lymphadenopathy was suspected upon preoperative imaging or observed during surgery. The majority of patients with non-organ-confined disease received cisplatinbased adjuvant chemotherapy. Tumours were staged according to the American Joint Committee on Cancer ( $6^{\text {th }}$ edition) staging system. ${ }^{21}$ Tumour grades were assessed according to the 1998 World Health Organization classification system. ${ }^{22}$ All specimens were histologically confirmed to be urothelial carcinoma. LVI was defined as the presence of tumour cells in an endothelium-lined space without underlying muscular walls. ${ }^{13}$ Tumour multifocality was defined as the synchronous presence of two or more pathologically confirmed tumours in any location (renal pelvis or ureter). ${ }^{23}$

\section{Followup regimen}

Followup examinations included cystoscopy, urine cytology, chest X-ray, and CT scanning. Cystoscopy and urine cytology were performed at three, six, and 12 months post-surgery, and yearly thereafter. Image analyses were performed at three, six, and 12 months after RNU, and then every six months from 1-5 years post-surgery. Scans were performed annually thereafter. In this study, locoregional/distant metas- tasis was defined as a locoregional recurrence or a new distant metastasis based on clinical and radiographic findings. Metastasis-free survival (MFS) was defined as the period between surgery and the detection of locoregional recurrence, distant metastasis, or the study's endpoint. Time to CSS was calculated as the time from surgery to the date of cancer-attributable mortality.

\section{Statistical analysis}

To evaluate patient outcomes, subjects were divided into node negative (N0, Group 1); node positive ( $\mathrm{N}+$, Group 2); no LND without LVI (NxLVI-, Group 3); and no LND with LVI present (NxLVI+, Group 4). For comparison of variables, differences in variables with continuous distributions across dichotomous categories were assessed using ANOVA. The Fisher's exact and Pearson chi-square tests were used to evaluate the association between categorical variables. The Kaplan-Meier method was used to draw survival curves. The log-rank test was used to assess significance, with $p \leq 0.05$ considered statistically significant. Potential prognostic factors were established by univariate analyses and only factors considered significant were entered into multivariate Cox proportional hazards regression models. All statistical analyses were performed using the SPSS v.18.0 (IBM Corp., Armonk, NY, U.S.).

\section{Results}

The mean age was 66.26 years. Of 505 patients included in the study, 94 (18.6\%) had LVI. Regional LND was performed in 287 (56.8\%) patients, of which $28(9.8 \%)$ were $\mathrm{N}+$. The number of patients in each group was: $259(51.3 \%)$ in Group 1, 28 (5.5\%) in Group 2, 181(35.8\%) in Group 3, and 37 $(7.3 \%)$ in Group 4.

Differences in pre- and postoperative characteristics among the groups stratified by the presence of LNs and LVI are summarized in Table 1. Regarding clinical N stage, most patients $(78.6 \%)$ in Group 2 had positive LNs in the preoperative CT images. Patients in Group 2 also had larger tumours than those in the other groups. Considering the pathologic characteristics of the tumour specimens, statistically significant differences were found for pathologic $T$ stage $(p<0.001)$, surgical margin status $(p=0.015)$, multifocality $(p=0.008)$, and tumour grade $(p=0.009)$.

The median followup period was 38.4 months (interquartile range [IQR] 15.6-56.5). One hundred and nine (109) patients $(21.6 \%)$ received adjuvant systemic chemotherapy. During the followup period, 173 patients (34.3\%) had bladder recurrence after a median followup time of 17.0 months (IQR 8.4-36.0). Overall, locoregional recurrence/distant metastasis occurred in 129 patients (25.5\%) after a median period of 25.5 months (IQR 12.0-51.4). One hundred and 


\begin{tabular}{|c|c|c|c|c|}
\hline & Group 1 (n=259) & Group 2 (n=28) & Group 3 (n=181) & Group 4 (n=37) \\
\hline Age (years, mean \pm SD) & $66.05 \pm 10.67$ & $66.07 \pm 9.40$ & $65.69 \pm 10.56$ & $70.68 \pm 9.09$ \\
\hline BMI $\left(\mathrm{kg} / \mathrm{m}^{2}\right)$ & $23.6 \pm 3.2$ & $23.4 \pm 2.4$ & $23.9 \pm 3.0$ & $24.3 \pm 2.9$ \\
\hline \multicolumn{5}{|l|}{ Gender (\%) } \\
\hline Male & $174(67.2)$ & $22(78.6)$ & $125(69.1)$ & $27(73.0)$ \\
\hline Female & 85 (32.8) & $6(21.4)$ & $56(30.9)$ & $10(27.0)$ \\
\hline \multicolumn{5}{|l|}{ Smoking status (\%) } \\
\hline No & $166(64.2)$ & $17(60.7)$ & $116(64.1)$ & $25(67.6)$ \\
\hline Yes & $93(35.8)$ & $11(39.3)$ & 65 (35.9) & $12(32.4)$ \\
\hline \multicolumn{5}{|l|}{ Laterality (\%) } \\
\hline Left & $147(56.8)$ & $17(60.7)$ & $88(48.6)$ & $16(43.2)$ \\
\hline Right & $112(43.2)$ & $11(39.3)$ & $93(51.4)$ & $21(56.8)$ \\
\hline \multicolumn{5}{|l|}{ Clinical N stage } \\
\hline No & $240(92.7)$ & $6(21.4)$ & $180(99.4)$ & 34 (91.9) \\
\hline $\mathrm{N}+$ & $19(7.3)$ & $22(78.6)$ & $1(0.6)$ & $3(8.1)$ \\
\hline Tumour size $(\mathrm{mm}$, mean $\pm \mathrm{SD})$ & $38.1 \pm 24.7$ & $52.9 \pm 30.7$ & $36.7 \pm 26.5$ & $40.8 \pm 22.8$ \\
\hline \multicolumn{5}{|l|}{ Tumour location (\%) } \\
\hline Renal pelvis & $94(36.3)$ & $11(39.3)$ & $64(35.4)$ & $16(43.2)$ \\
\hline Ureter & $136(52.5)$ & $13(46.4)$ & $90(49.7)$ & $13(35.1)$ \\
\hline Both & $29(11.2)$ & $4(14.3)$ & 27 (14.9) & $8(21.7)$ \\
\hline \multicolumn{5}{|l|}{ Previous or concomitant BC (\%) } \\
\hline No & 207 (79.9) & $24(85.7)$ & $147(81.2)$ & $30(81.1)$ \\
\hline Yes & $52(20.1)$ & $4(14.3)$ & $34(18.8)$ & $7(18.9)$ \\
\hline \multicolumn{5}{|l|}{ Bladder cuff resection (\%) } \\
\hline No & $29(11.2)$ & $4(14.3)$ & $21(11.6)$ & $6(16.2)$ \\
\hline Yes & $230(88.8)$ & $24(85.7)$ & $160(88.4)$ & $31(83.8)$ \\
\hline \multicolumn{5}{|l|}{ Multifocality (\%) } \\
\hline No & $164(63.3)$ & $17(60.7)$ & $141(77.9)$ & $27(73.0)$ \\
\hline Yes & $95(36.7)$ & $11(39.3)$ & $40(22.1)$ & $10(27.0)$ \\
\hline \multicolumn{5}{|l|}{ Pathologic T stage, (\%) } \\
\hline $\mathrm{Ta}, \mathrm{T} 1, \mathrm{CIS}, \mathrm{T} 2$ & $141(54.4)$ & $5(17.9)$ & $137(75.7)$ & $12(32.4)$ \\
\hline T3-T4 & $118(45.6)$ & $23(82.1)$ & $44(24.3)$ & $25(67.6)$ \\
\hline \multicolumn{5}{|l|}{ Grade (\%) } \\
\hline Low & 81 (31.3) & $3(10.7)$ & $45(24.9)$ & $4(10.8)$ \\
\hline High & $178(68.7)$ & $25(89.3)$ & $136(75.1)$ & $33(89.2)$ \\
\hline \multicolumn{5}{|l|}{ Margin status, (\%) } \\
\hline Negative & 245 (94.6) & $24(85.7)$ & $177(97.8)$ & $33(89.2)$ \\
\hline Positive & $14(5.4)$ & $4(14.3)$ & $4(2.2)$ & $4(10.8)$ \\
\hline
\end{tabular}

BC: bladder cancer; BMI: body mass index; SD: standard deviation.

eleven (111) patients (22.0\%) died; 88 deaths (17.4\%) were directly related to cancer. Kaplan-Meier curves were used to assess bladder recurrence, MFS, CCS, and overall survival (OS) according to LN and LVI status. No statistically significant differences in bladder recurrence were observed among the four groups (Fig. 1A). Group 2 had the worst prognostic outcomes regarding MFS and Group 4 patients had significantly worse MFS than Groups 1 and 3 (Fig. 1B). LN and LVI status (Groups 2 and 4) was helpful in predicting MFS compared to Group 1 in univariate Cox analysis; however, Group 4 did not appear as an independent predictor of MFS
(Table 2). Considering CCS and OS, the poorest oncologic outcomes were found in Group 2 (Figs. 2A and 2B), and no differences in CCS and OS were detected between Groups 1 and 4 (Figs. 2A and B).

In the subgroup of patients with $\mathrm{Nx}$ disease (Group 3 vs. Group 4), LVI status had a negative impact on MFS and CSS ( $p=0.032$ and $p=0.035$, respectively; Figs. $1 B$ and $2 A)$; however, LVI was not an independent prognostic factor for MFS and CSS in multivariate analysis (supplementary Tables 1 and 2). Among the patients who underwent LND (only including Groups 1 and 2), LVI was a significant prognostic 
Yoo et al.

\begin{tabular}{|c|c|c|c|c|}
\hline \multirow{2}{*}{ Parameters } & \multicolumn{2}{|c|}{ Univariate analysis } & \multicolumn{2}{|c|}{ Multivariate analysis } \\
\hline & HR (95\% Cl) & $p$ value & HR (95\% Cl) & p value \\
\hline Age & $1.020(1.002-1.038)$ & 0.025 & $1.017(0.997-1.036)$ & 0.096 \\
\hline Gender (male vs. female) & $0.951(0.653-1.385)$ & 0.795 & - & - \\
\hline Smoking (no vs. yes) & $0.952(0.618-1.466)$ & 0.823 & - & - \\
\hline Tumour size & $1.007(1.001-1.012)$ & 0.018 & $1.000(0.994-1.006)$ & 0.997 \\
\hline \multicolumn{5}{|l|}{ Tumour location } \\
\hline Renal pelvis & 1 & - & 1 & - \\
\hline Ureter & $1.176(0.793-1.743)$ & 0.42 & $0.971(0.637-1.480)$ & 0.892 \\
\hline Both & $1.847(1.123-3.038)$ & 0.016 & $1.613(0.942-2.761)$ & 0.081 \\
\hline Bladder cuff resection (no vs. yes) & $0.274(0.195-0.917)$ & 0.019 & $0.629(0.370-1.069)$ & 0.087 \\
\hline Multifocality (no vs. yes) & $1.180(0.821-1.695)$ & 0.371 & - & - \\
\hline Pathologic T stage (Ta, CIS, T1-2 vs. T3-4) & $3.274(2.051-5.226)$ & $<0.001$ & $1.786(1.065-2.996)$ & 0.028 \\
\hline Grade (low vs. high) & $4.992(2.686-9.278)$ & $<0.001$ & $4.251(2.146-8.421)$ & $<0.001$ \\
\hline Concomitant CIS (no vs. yes) & $0.999(0.481-2.031)$ & 0.975 & - & - \\
\hline Margin status (no vs. yes) & $4.979(3.054-8.116)$ & $<0.001$ & $3.741(2.195-6.375)$ & $<0.001$ \\
\hline \multicolumn{5}{|l|}{ LVI and LN status } \\
\hline Group 1 (NO) & 1 & - & 1 & - \\
\hline Group $2(\mathrm{~N}+)$ & $6.834(4.061-11.500)$ & $<0.001$ & $5.896(3.428-10.141)$ & $<0.001$ \\
\hline Group 3 (NxLVI-) & $1.203(0.802-1.805)$ & 0.372 & $1.187(0.778-1.811)$ & 0.425 \\
\hline Group 4 (NxLVI+) & $2.281(1.283-4.058)$ & 0.005 & $1.549(0.861-2.786)$ & 0.144 \\
\hline
\end{tabular}

Cl: confidence interval; CIS: carcinoma in situ; HR: hazard ratio; LVI: lymphovascular invasion; LN: lymph node; UTUC: upper tract urothelial carcinoma.

marker predicting the MFS, CCS, and OS (supplementary Fig. 1).

\section{Discussion}

In the present study, we showed that $\mathrm{N}+$ patients (Group

2) had worse prognostic outcomes regarding MFS, CSS, and OS than those in the other groups. According to the European guidelines on UTUC, LND should be performed in association with RNU for better tumour staging and to improve prognosis; ${ }^{10}$ however, LND is not routinely performed during RNU and many patients will experience regional LN relapse during followup. ${ }^{24}$ Therefore, knowledge of LN status is important because it influences patient

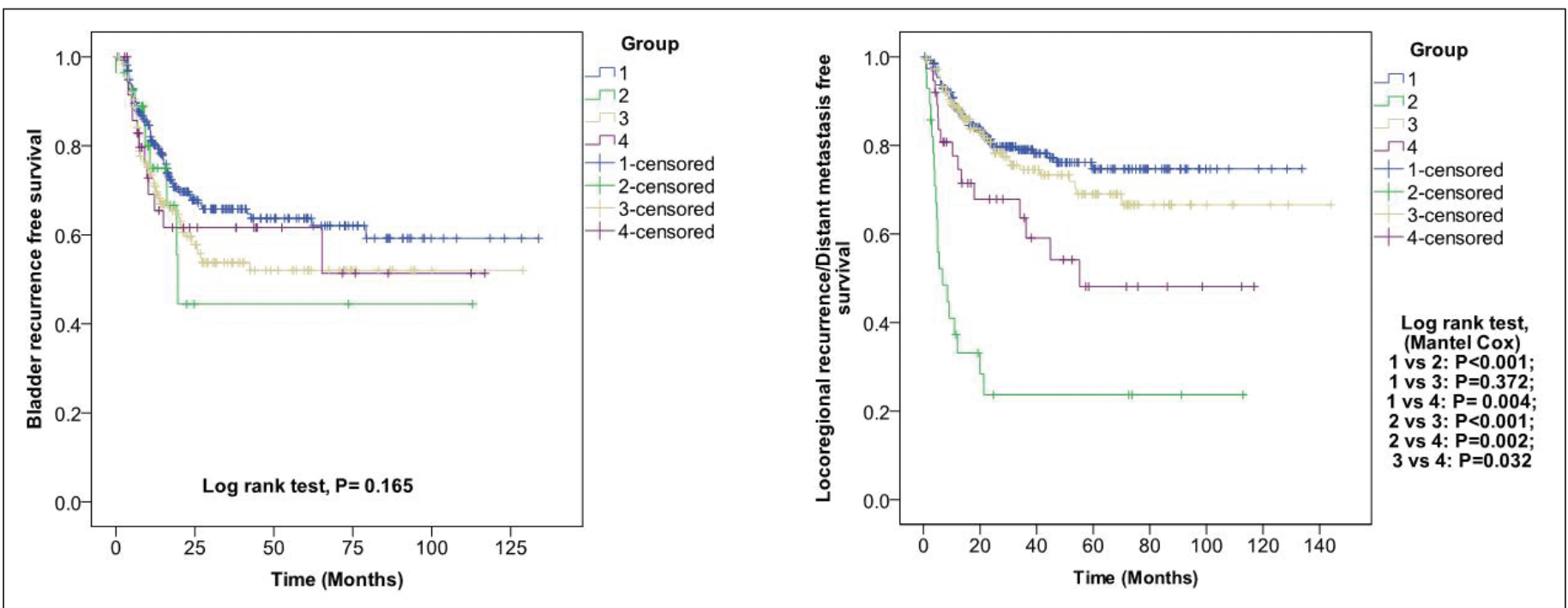

Fig 1. Effect of lymph node (LN) and lymphovasclular invasion (LVI) status on (A) bladder recurrence; and (B) locoregional recurrence/distant metastasis after radical nephroureterctomy. Patients were divided into node negative (N0, Group 1); node positive ( $\mathrm{N+}$, Group 2); no lymph node dissection (LND) without LVI (NxLVI-, Group 3); and no LND with LVI present (NxLVI+, Group 4). 


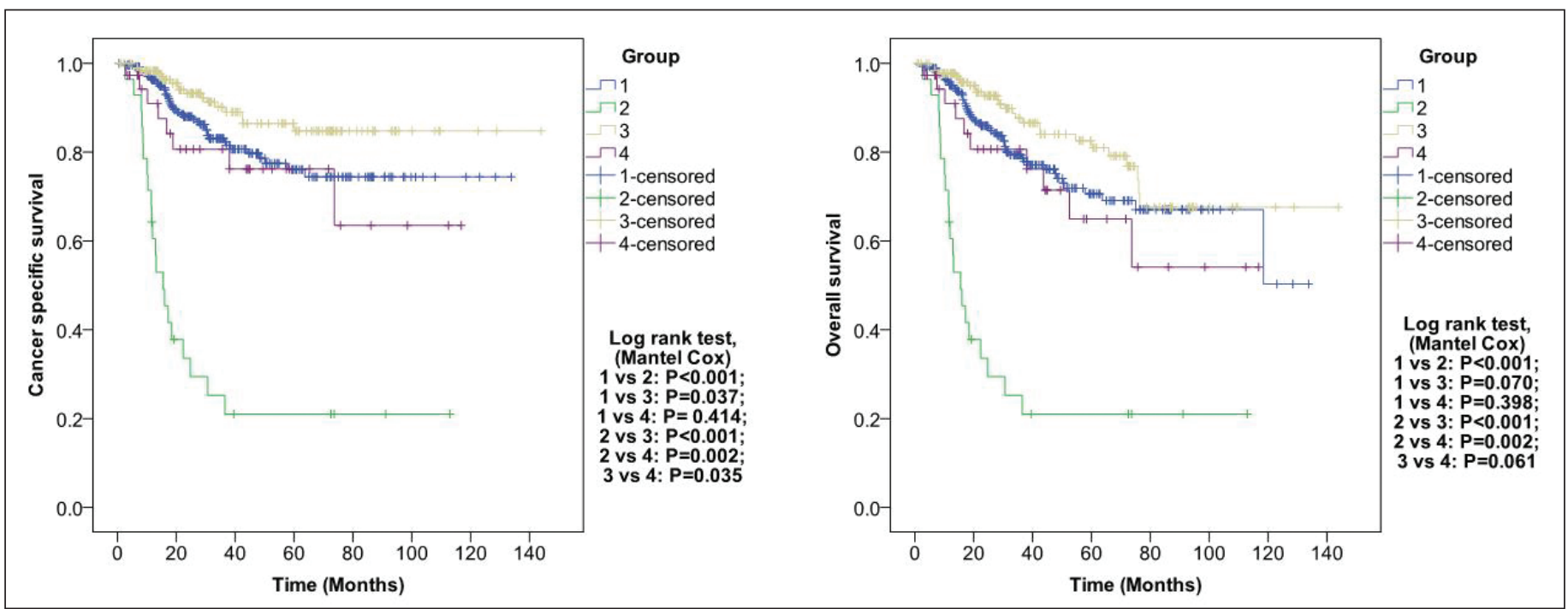

Fig 2. Effect of lymph node (LN) and lymphovasclular invasion (LVI) status on (A) cancer-specific survival; and (B) overall survival after radical nephroureterctomy. Patients were divided into node negative (NO, Group 1); node positive (N+, Group 2); no lymph node dissection (LND) without LVI (NxLVI-, Group 3); and no LND with LVI present (NxLVI+, Group 4).

counselling and, more importantly, clinical decision-making regarding followup scheduling and adjuvant chemotherapy. ${ }^{25,26}$

A recent meta-analysis identified $L V I$ as a strong predictor of poor prognosis among patients with UTUC. ${ }^{27}$ Consistent with previous studies, our results showed that Group 4 $(\mathrm{NxLVI+)}$ patients had worse pathological features than Groups 1 (NO) and 3 (NxLVI-) patients in terms of T stage and grade; however, despite the fact that Group 4 patients had worse MFS than those in Groups 1 and 3 in the univariate analysis, Group 4 (NxLVI+) was not an independent predictor of MFS compared to the patients in Group 1 (N0) based on multivariate Cox regression analysis. Furthermore, patients in Group $4(\mathrm{NxLVI}+)$ showed no additional prognostic advantages regarding OS and CSS compared to those in Group 1 (N0). Therefore, whether LVI is a universal prognostic marker for UTUC and a surrogate for LN involvement remains unclear. Previous studies supporting our results showed that LVI is not an independent predictor of MFS ${ }^{28-}$ 31 and CCS. 28,29,32,33 A recent study among Korean UTUC patients showed that LVI was not a significant predictor for OS. ${ }^{9}$ In a Taiwanese study by Lee et al, LVI represented a significant prognosticator for both CSS and MFS in multivariate analysis only in patients with ureteral tumours, but not in those with pyelocaliceal tumours. ${ }^{34}$ In other words, LVI failed to be independently associated with CSS and MFS in pyelocaliceal tumours. They concluded that the prognostic value of $L V I$ is further highlighted with respect to ureteral tumours specifically.

In the present study, subgroup analysis of patients with $N x$ disease showed that LVI status had a negative impact on MFS and CSS on univariate analysis; however, we failed to find a negative impact of LVI on RFS and CSS on multivariate analysis. These results were in accordance with the report from Colin et al, ${ }^{35}$ who assessed the risk factors of metastasis in UTUC patients undergoing RNU without LND. LVI status was not significantly associated with worse MFS on multivariate analysis. ${ }^{35}$ In the present study, the independent prognostic factors for RFS and CSS among the patients with $\mathrm{Nx}$ disease were pathologic $\mathrm{T}$ stage and positive surgical margin. These factors were also identified as independent prognostic indicators in the subgroup of patients with $\mathrm{pNO} / \mathrm{x}$ disease in a recent study; ${ }_{i}^{36}$ however, this study showed that LVI was a significant prognostic factor on multivariate analysis. In our subgroup analysis including $\mathrm{N} 0$ and $\mathrm{N} 1$ patients, LVI remained a useful predictor for MFS, CSS, and OS, in agreement with previous results, ${ }^{36}$ which suggests that LVI is an important factor in patients who undergo LND, but not in those who do not undergo LND. Therefore, LND, which lacks standardization in UTUC, should be performed to improve the prediction of prognosis and the establishment of an adjuvant therapy schedule. A recent study showed that LVI was a significant predictor for CSS in the Nx group and might be used as a surrogate marker in patients who do not undergo LDN at the time of surgery; ${ }^{20}$ however, this study had a limited population size $(n=131)$, and other wellknown independent predictors, such as pathologic T stage, were not included as significant variables in multivariate analysis. Therefore, the establishment of standardized guidelines for the management of UTUC patients requires further investigation.

Our study had several limitations associated with its retrospective nature. Although we could control for numerous potential confounders, we were unable to control for 
Yoo et al.

surgeon and pathologist experience, treatment decisions (such as patient and surgeon preferences), or the anatomical template of the preferred LND. Relatively short periods of followup warranted consideration. Moreover, we did not report the information of the $\mathrm{LN}$ yield from surgeries at the centre. The other limitation of our study is the small number of cases in Groups 2 and 4.

\section{Conclusions}

Although LVI was a predictor of poor outcome in patients with UTUC, it could not replace LN positivity as a prognostic marker. In particular, LVI did not provide important prognostic information in patients with $\mathrm{Nx}$. Therefore, LVI may not be used as a substitute for nodal status in patients who do not undergo LND at the time of surgery.

Competing interests: The authors declare no competing personal or financial interests.

Acknowledgement: This research was supported by the Bio \& Medical Technology Development Program of the National Research Foundation (NRF) funded by the Ministry of Science, ICT\& Future Planning (NRF-2014M3A9D3033887) and by the National Research Foundation of Korea (NRF) grant funded by the Korea government (MSIP) (No. NRF-2014RTA2A1A09006983).

This paper has been peer-reviewed.

\section{References}

1. Kapoor $A$, Dason $S$, Allard $C B$, et al. The impact of method of distal ureter management during radical nephroureterectomy on tumour recurrence. Can Urol Assoc J 2014;8:E845-52. http://dx.doi. org/10.5489/cuaj.1985

2. Kim BW, Ha YS, Lee JN, et al. Effects of previous or synchronous non-muscle-invasive bladder cancer on clinical results after radical nephroureterectomy for upper tract urothelial carcinoma: A multi-institutional study. Urol J 2015; 12:2233-9.

3. Trudeau V, Gandaglia G, Shiffmann J, et al. Robot-assisted versus laparoscopic nephroureterectomy for upper-tract urothelial cancer: A population-based assessment of costs and perioperative outcomes. Can Urol Assoc J 2014;8:E695-701. http://dx.doi.org/10.5489/cuai.2051

4. Leveridge MJ. Mining the data on UTUC management. Can Urol Assoc J 2012;6:463-4.

5. Metcalfe M, Kassouf W, Rendon R, et al. Regional differences in practice patterns and associated outcomes for upper tract urothelial carcinoma in Canada. Can Urol Assoc J 2012;6:455-62.

6. Ehdaie B, Shariat SF, Savage C, et al. Postoperative nomogram for disease recurrence and cancer-specific death for upper tract urothelial carcinoma: comparison to American Joint Committee on Cancer staging classification. Urol J 2014;11:1435-41.

7. Tawfiek ER, Bagley DH. Upper-tract transitional cell carcinoma. Urology 1997;50:321-9. http://dx.doi. org/10.1016/S0090-4295(97)00230-6

8. Margulis V, Shariat SF, Matin SF, et al. Outcomes of radical nephroureterectomy: A series from the Upper Tract Urothelial Carcinoma Collaboration. Cancer 2009;115:1224-33. http://dx.doi.org/10.1002/ cncr. 24135

9. Cho YH, Seo YH, Chung SJ, et al. Predictors of intravesical recurrence after radical nephroureterectomy for upper urinary tract urothelial carcinoma: An inflammation-based prognostic score. Korean I Urol 2014:55:453-9. http://dx.doi.org/10.4111/kju.2014.55.7.453

10. Roupret $M$, Zigeuner $R$, Palou J, et al. European guidelines for the diagnosis and management of upper urinary tract urothelial cell carcinomas: 2011 update. Eur Urol 2011;59:584-94. http://dx.doi. org/10.1016/i.eururo.2010.12.042
11. Lee JN, Kim BS, Kim HT, et al. Oncologic outcomes of laparoscopic nephroureterectomy for pT3 upper urinary tract urothelial carcinoma. Minerva Urol Nefrol 2014;66:157-64.

12. Tanaka N, Kikuchi E, Kanao K, et al. A multi-institutional validation of the prognostic value of the neutrophilto-lymphocyte ratio for upper tract urothelial carcinoma treated with radical nephroureterectomy. Ann Surg Oncol 2014;21:4041-8. http://dx.doi.org/10.1245/s10434-014-3830-3

13. Novara $\mathrm{G}$, Matsumoto K, Kassouf W, et al. Prognostic role of lymphovascular invasion in patients with urothelial carcinoma of the upper urinary tract: An international validation study. Eur Urol 2010;57:106471. http://dx.doi.org/10.1016/i.eururo.2009.12.029

14. Alitalo K, Mohla S, Ruoslahti E. Lymphangiogenesis and cancer: meeting report. Cancer Res 2004;64:92259. htrp://dx.doi.org/10.1158/0008-5472.CAN-04-2475

15. Kikuchi E, Margulis V, Karakiewicz Pl, et al. Lymphovascular invasion predicts clinical outcomes in patients with node-negative upper tract urothelial carcinoma. J Clin Oncol 2009;27:612-8. http:// dx.doi.org/10.1200/JC0.2008.17.2361

16. Bolenz C, Fernandez MI, Trojan L, et al. Lymphovascular invasion and pathologic tumour stage are significant outcome predictors for patients with upper tract urothelial carcinoma. Urology 2008;72:364-9. http://dx.doi.org/10.1016/i.urology.2008.04.032

17. Saito K, Kawakami S, Fujii Y, et al. Lymphovascular invasion is independently associated with poor prognosis in patients with localized upper urinary tract urothelial carcinoma treated surgically. J Urol 2007;178:2291-6; discussion 6. http://dx.doi.org/10.1016/i.juro.2007.08.019

18. Kikuchi E, Horiguchi Y, Nakashima J, et al. Lymphovascular invasion independently predicts increased disease specific survival in patients with transitional cell carcinoma of the upper urinary tract. J Urol 2005;174:2120-3; discussion 4. http://dx.doi.org/10.1097/01.ju.0000181801.22474.8b

19. Geller R, Hemal S, Manny T. Lymphadenectomy for renal cell carcinoma and urothelial carcinoma of the upper urinary tract: Analysis of evidence in the minimally invasive era. Minerva Med 2013;104:261-72.

20. Pedrosa JA, Kaimakliotis HZ, Monn MF, et al. Can lymphovascular invasion be used as a surrogate for lymph node involvement in patients with upper tract urothelial carcinoma? J Urol 2014;191:Se911. http://dx.doi.org/10.1016/i.juro.2014.02.2481

21. Greene FL. The American Joint Committee on Cancer: Updating the strategies in cancer staging. Bull Am Coll Surg 2002;87:13-5

22. Epstein Jl, Amin MB, Reuter VR, et al. The World Health Organization/International Society of Urological Pathology consensus classification of urothelial (transitional cell) neoplasms of the urinary bladder. Bladder Consensus Conference Committee. Am J Surg Pathol 1998;22:1435-48. http://dx.doi. org/10.1097/00000478-199812000-00001

23. Chromecki TF, Cha EK, Fajkovic H, et al. The impact of tumour multifocality on outcomes in patients treated with radical nephroureterectomy. Eur Urol 2012;61:245-53. http://dx.doi.org/10.1016/i. eururo.2011.09.017

24. Ouzzane $A$, Colin $P$, Ghoneim TP, et al. The impact of lymph node status and features on oncological outcomes in urothelial carcinoma of the upper urinary tract (UTUC) treated by nephroureterectomy. World J Urol 2013;31:189-97. http://dx.doi.org/10.1007/s00345-012-0983-1

25. Hellenthal NJ, Shariat SF, Margulis V, et al. Adjuvant chemotherapy for high risk upper tract urothelial carcinoma: Results from the Upper Tract Urothelial Carcinoma Collaboration. J Urol 2009;182:900-6. http://dx.doi.org/10.1016/i.juro.2009.05.011

26. Vassilakopoulou M, de la Motte Rouge $\mathrm{T}$, Colin $\mathrm{P}$, et al. Outcomes after adjuvant chemotherapy in the treatment of high-risk urothelial carcinoma of the upper urinary tract (UUT-UC): Results from a large multicenter collaborative study. Cancer 2011;117:5500-8. http://dx.doi.org/10.1002/cncr.26172

27. $\mathrm{Ku} \mathrm{JH}$, Byun SS, Jeong $\mathrm{H}$, et al. Lymphovascular invasion as a prognostic factor in the upper urinary tract urothelial carcinoma: A systematic review and meta-analysis. Eur J Cancer 2013;49:2665-80. http:// dx.doi.org/10.1016/i.ejca.2013.04.016

28. Berger A, Haber GP, Kamoi K, et al. Laparoscopic radical nephroureterectomy for upper tract transitional cell carcinoma: Oncological outcomes at 7 years. J Urol 2008;180:849-54; discussion 54. http://dx.doi. org/10.1016/i.juro.2008.05.042

29. Colin P, Ouzzane A, Yates DR, et al. Influence of positive surgical margin status after radical nephroureterectomy on upper urinary tract urothelial carcinoma survival. Ann Surg Oncol 2012;19:3613-20. http:// dx.doi.org/10.1245/s10434-012-2453-9

30. Kawashima A, Nakai Y, Nakayama $M$, et al. The result of adjuvant chemotherapy for localized pT3 upper urinary tract carcinoma in a multi-nstitutional study. World J Urol 2012;30:701-6. http://dx.doi. org/10.1007/s00345-011-0775-z

31. Milojevic B, Diokic M, Sipetic-Grujicic $S$, et al. Prognostic significance of non-muscle-invasive bladder tumour history in patients with upper urinary tract urothelial carcinoma. Urol Oncol 2013;31:1615-20. http:// dx.doi.org/10.1016/j.urolonc.2012.03.004

32. Cho KS, Cho NH, Park SY, et al. Prognostic impact of peripelvic fat invasion in pT3 renal pelvic transitional cell carcinoma. J Korean Med Sci 2008;23:434-8. http://dx.doi.org/10.3346/ikms.2008.23.3.434

33. Hong $B$, Park $S$, Hong JH, et al. Prognostic value of lymphovascular invasion in transitional cell carcinoma of upper urinary tract. Urology 2005;65:692-6. http://dx.doi.org/10.1016/i.urology.2004.11.001 
34. Lee $\mathrm{HY}$, Li CC, Huang $\mathrm{CN}$, et al. Prognostic significance of lymphovascular invasion in upper urinary tract urothelial carcinoma is influenced by tumour location. Ann Surg Oncol 2015;22:1392-400. http:// dx.doi.org/10.1245/s10434-014-4103-x

35. Colin $P$, Ghoneim TP, Nison L, et al. Risk stratification of metastatic recurrence in invasive upper urinary tract carcinoma after radical nephroureterectomy without lymphadenectomy. World J Urol 2014;32:507-12. http://dx.doi.org/10.1007/s00345-013-1116-1

36. Hurel $S$, Roupret $M$, Ouzzane $A$, et al. Impact of lymphovascular invasion on oncological outcomes in patients with upper tract urothelial carcinoma after radical nephroureterectomy. BJU Int 2013;111:1199207. http://dx.doi.org/10.1111/bju.12116
Correspondence: Dr. Tae Gyun Kwon, Department of Urology, Kyungpook National University Medical Center, Daegu, Korea; tgkwon@knu.ac.kr

\begin{tabular}{|c|c|c|c|c|}
\hline \multicolumn{5}{|c|}{$\begin{array}{l}\text { Supplementary Table 1. Subgroup analyses of the patients with Nx: Univariate and multivariate Cox regression analyses t } \\
\text { identify predictors of locoregional recurrence/distant metastasis }\end{array}$} \\
\hline \multirow{2}{*}{ Parameters } & \multicolumn{2}{|c|}{ Univariate analysis } & \multicolumn{2}{|c|}{ Multivariate analysis } \\
\hline & HR $(95 \% \mathrm{CI})$ & $p$ value & HR (95\% Cl) & p value \\
\hline Age & $1.013(0.987-1.039)$ & 0.34 & - & - \\
\hline Gender (male vs. female) & $0.660(0.356-1.223)$ & 0.186 & - & - \\
\hline Smoking (no vs. yes) & $1.045(0.588-1.857)$ & 0.88 & - & - \\
\hline Tumour size & $1.000(0.991-1.009)$ & 0.959 & - & - \\
\hline \multicolumn{5}{|l|}{ Tumour location } \\
\hline Renal pelvis & 1 & - & - & - \\
\hline Ureter & $1.489(0.805-2.755)$ & 0.205 & - & - \\
\hline Both & $1.966(0.959-4.030)$ & 0.065 & - & - \\
\hline Bladder cuff resection (no vs. yes) & $0.598(0.302-1.181)$ & 0.139 & - & - \\
\hline Multifocality (no vs. yes) & $1.224(0.694-2.156)$ & 0.485 & - & - \\
\hline Pathologic T stage (Ta, CIS, T1-2 vs. T3-4) & $2.898(1.729-4.859)$ & $<0.001$ & $2.355(1.340-4.256)$ & 0.005 \\
\hline Grade (low vs. high) & $2.802(1.267-6.201)$ & 0.011 & $1.771(0.760-4.123)$ & 0.185 \\
\hline Concomitant CIS (no vs. yes) & $1.497(0.678-3.306)$ & 0.318 & - & - \\
\hline Margin status (no vs. yes) & $5.665(2.561-12.530)$ & $<0.001$ & $4.556(1.983-10.465)$ & $<0.001$ \\
\hline LVI (no vs. yes) & $1.886(1.047-3.395)$ & 0.035 & $1.063(0.547-2.066)$ & 0.185 \\
\hline
\end{tabular}

Cl: confidence interval; CIS: carcinoma in situ; HR: hazard ratio; LVI: Iymphovascular invasion; UTUC: upper tract urothelial carcinoma.

\begin{tabular}{|c|c|c|c|c|}
\hline \multirow{2}{*}{ Parameters } & \multicolumn{2}{|c|}{ Univariate analysis } & \multicolumn{2}{|c|}{ Multivariate analysis } \\
\hline & HR (95\% Cl) & p value & HR (95\% Cl) & p value \\
\hline Age & $1.034(0.991-1.078)$ & 0.126 & - & - \\
\hline Gender (male vs. female) & $1.095(0.472-2.538)$ & 0.833 & - & - \\
\hline Smoking (no vs. yes) & $0.621(0.227-1.697)$ & 0.353 & - & - \\
\hline Tumour size & $1.003(0.991-1.015)$ & 0.639 & - & - \\
\hline \multicolumn{5}{|l|}{ Tumour location } \\
\hline Renal pelvis & 1 & - & - & - \\
\hline Ureter & $0.813(0.305-2.169)$ & 0.679 & - & - \\
\hline Both & $2.280(0.878-5.922)$ & 0.091 & - & - \\
\hline Bladder cuff resection (no vs. yes) & $0.408(0.163-1.024)$ & 0.056 & - & - \\
\hline Multifocality (no vs. yes) & $1.507(0.663-3.423)$ & 0.328 & - & - \\
\hline Pathologic T stage (Ta, CIS, T1-2 vs. T3-4) & $4.903(2.161-11.126)$ & $<0.001$ & $4.432(1.823-10.771)$ & 0.001 \\
\hline Grade (low vs. high) & $4.244(0.998-18.050)$ & 0.05 & - & - \\
\hline Concomitant $\mathrm{CIS}$ (no vs. yes) & $0.960(0.226-4.077)$ & 0.956 & - & - \\
\hline Margin status (no vs. yes) & $5.654(1.928-16.582)$ & $<0.002$ & $4.238(1.382-13.002)$ & 0.012 \\
\hline LVI (no vs. yes) & $2.406(1.037-5.581)$ & 0.041 & $1.073(0.419-2.749)$ & 0.185 \\
\hline
\end{tabular}


Yoo et al.

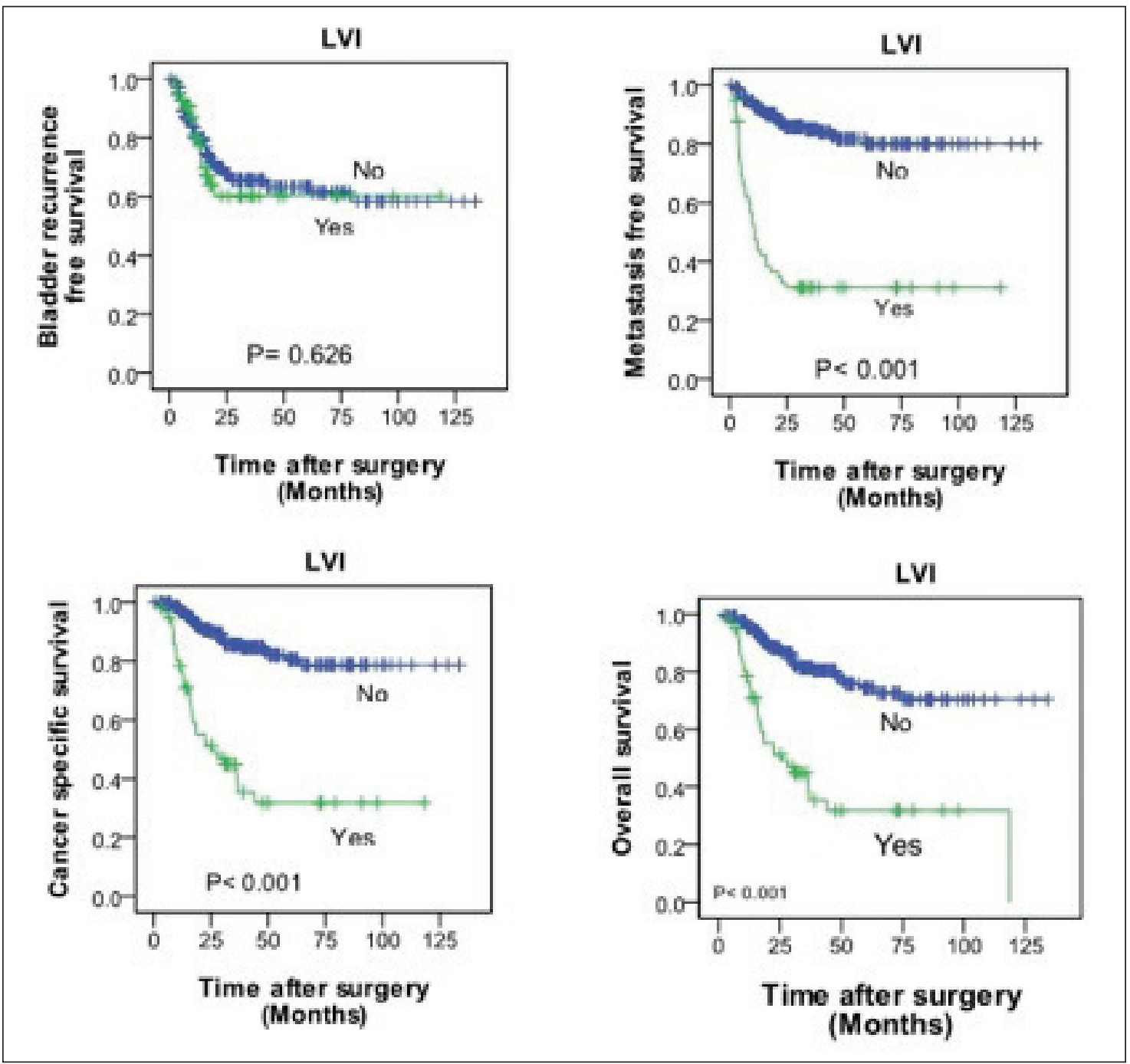

Suppl. Fig 1. Prognostic values of lymphovascular invasion (LVI) in patients with lymph node dissection (LND) (N0 and N1). 